\title{
Chinese institute is an innovation in theory
}

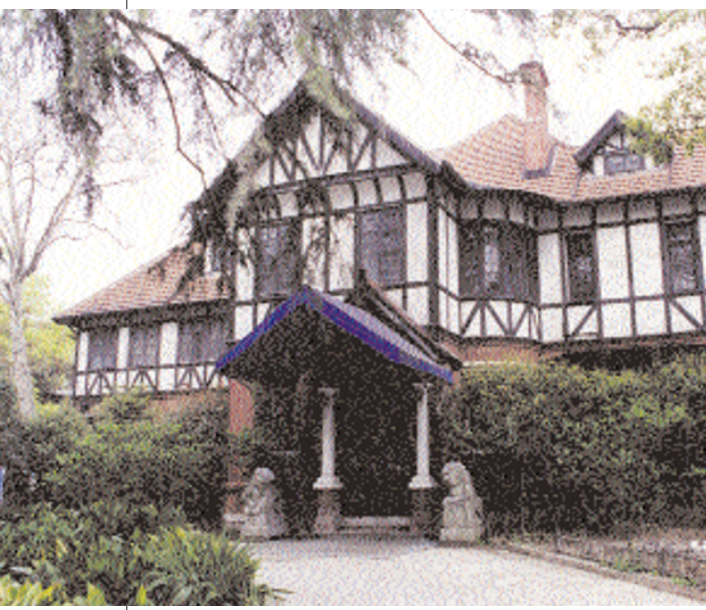

Mould-breaking: the Chinese Academy of Sciences is going multidisciplinary at its new institute.

\section{David Cyranoski, Shanghai}

Interdisciplinary boundaries are rarely stricter than those that separate the 100-plus research institutes of the Chinese Academy of Sciences, home to some 40,000 of the country's researchers. But the academy is moving tentatively towards breaking that mould by setting up its first multidisciplinary institute.

The Shanghai-based Institute for Advanced Studies will eventually employ 20 research fellows from various disciplines and will tackle complex problems in biology, concentrating on their theoretical aspects.

"This is essential for China," says Uli Schwarz, a biologist at Germany's Max Planck Institute for Developmental Biology in Tübingen and a co-director of the new institute. "We need to create a new atmos-

\section{US strikes a deal on export rules}

Tony Reichhardt, Washington

The US government has compromised on export restrictions applying to researchers building satellites and other space hardware. But space scientists will still face obstacles in working with foreign colleagues, experts say.

The State Department issued an interim rule on its International Traffic in Arms Regulations (ITAR) on 29 March. Since 1999, satellites have been under the jurisdiction of ITAR. Scientists have grown concerned about their possible liability under the rules, which can require licensing not only for the export of satellites and spacecraft instruments, but also for technical discussions about them. As a result, some foreign-born researchers at US universities have been barred from fully participating in international space missions (see Nature 404, 321; 2000).

University lobby groups had pushed for a blanket ITAR exemption for scientists engaged in "fundamental research" where information is in the public domain. The new rule is "certainly not everything the universities wanted", according to Tim Brightbill, an attorney with law firm Wiley Rein \& Fielding, who advises academic and commercial clients on ITAR compliance.

Under the new rule, US universities will not need ITAR licences if they export satellite hardware or information to members of NATO, the European Union or the European Space Agency, and countries listed as "major non-NATO allies", such as Japan and Israel. But they still need a licence for exports and exchange of technical information with other foreign nationals, including researchers from India or China. And collaborators in approved countries would have to guarantee that no researchers from unapproved countries were receiving ITAR-restricted information.

Supporters of stiff export controls, who opposed NASA in negotiations over how much to ease the ITAR restrictions, are unlikely to concede any more ground, says Jack Shane, also of Wiley Rein \& Fielding. Sensitivity about terrorism will weaken the case of those who favour open access.

The State Department issued the regulation as an 'interim final rule', however, leaving the door open for additional public comment on it.

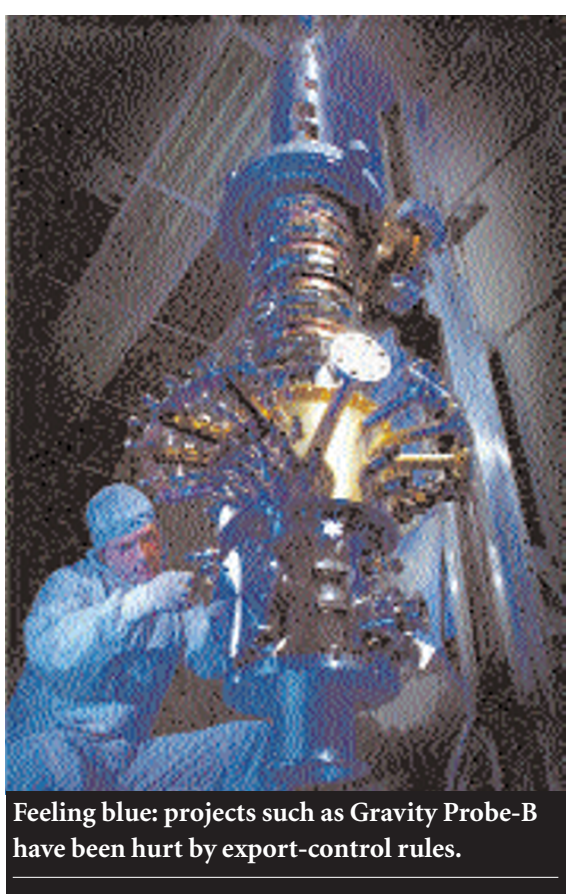

phere here," adds Schwarz, who will spend around a third of his time at the institute.

In an effort to bolster its scientific ties with China, Germany's Max Planck Society and other German sources will be providing part of the institute's US\$800,000 annual running costs.

Researchers are expected to spend between one month and a year at the institute. Officials promise that they will be free to follow their research in any direction. Those selected will specialize in fields of biology with a strong theoretical component, such as evolutionary biology, and will also investigate the interactions between science and society.

Organizers hope that research into science-based regulations, such as controls on pollution, and the history of science, will enable the institute to provide a broad-based view of the challenges faced by the Chinese Academy. "As scientists, we have to take note of the effect we are having on society," says Schwarz.

Fellows of the institute will be expected to publish their ideas on these subjects. If they need to do bench work, arrangements will be made for this to be carried out at the Shanghai Institute of Biological Sciences, says Yi Rao, a molecular neurobiologist at Washington University in St Louis and the institute's other co-director.

The institute held its first conference at the end of last month, on the theory of consciousness. International participants included Patricia Goldman-Rakic, a neurobiologist at Yale University School of Medicine; psychologist Willem Levelt from the Max Planck Institute for Pyscholinguistics at Nijmegen in the Netherlands; Christof Koch, a neuroscientist at the California Institute of Technology; and philosopher Thomas Metzinger of the Johannes Gutenberg University in Mainz, Germany.

"The conference was a great success in linking psychological and philosophical perspectives with well-grounded neurological science," says David Van Essen of Washington University in St Louis.

A second conference, on social behaviour, is to be held in September, when the institute plans to move to its permanent home on the campus of the Shanghai Institute of Biological Sciences, which is also part of the Chinese Academy of Sciences. The institute is already searching for further sources of funding, both inside and outside China.

Speaking privately, some participants at last month's meeting question whether an institute that will concentrate on theoretical questions will be able to maintain support from a government that is increasingly giving priority to applied science. 